\title{
Regarding the survey on perioperative diabetes medications and glucose control
}

\author{
M. S. Raghuraman, MD
}

Received: 13 May 2019/Revised: 13 May 2019/Accepted: 14 May 2019/Published online: 12 June 2019

(C) Canadian Anesthesiologists' Society 2019

\section{To the Editor,}

I read the recently published survey on the perioperative use of various group of anti-glycemic agents for the treatment of diabetes with great enthusiasm. ${ }^{1}$ I wish to add a few more points with regard to perioperative continuation of dipeptidyl peptidase-4 (DPP4) inhibitors and the optimal strategy for the control of glucose prior to proceeding to surgery.

Although Brown et al. ${ }^{1}$ mention that "the continuation of DPP4 inhibitors and other drugs perioperatively has been endorsed by some societies, and despite this, the application in practice is limited as they are yet to undergo clinical trials", few studies are available with regard to DPP4 inhibitors. Umpierrez et al. in their multicentre randomized pilot study reported that sitagliptin either alone or in combination with basal insulin was both effective and safe in controlling hyperglycemia in patients with type-2 diabetes. ${ }^{2}$ This was in both medical and general surgical patients. $^{2}$ Another study conducted on similar population by Pasquel et al. observed that sitagliptin plus basal insulin was as effective and safe as that of basal-bolus insulin therapy, in addition to its easier administration (lower frequency and dose) of insulin when compared with the basal-bolus method. ${ }^{3}$ Garg et al. observed that saxagliptin was non-inferior to basal-bolus insulin administration in non-critically ill patients admitted to general medical and surgical wards. ${ }^{4}$ Hence, I believe that we should be able to continue using DPP4 inhibitors perioperatively, albeit

This letter is accompanied by a reply. Please see Can J Anesth 2020; 67: this issue.

\section{S. Raghuraman, MD ( $\square)$}

Department of Anesthesiology, Sri Venkateshwaraa Medical College Hospital and Research Centre, Ariyur, Puducherry, India e-mail: drraghuram70@gmail.com based on these relatively few studies available. Nevertheless, I accept the fact that it will likely take quite some time for the perioperative team (anesthesiologists, surgeons, and other para-medial staff) to adopt this practice as we are generally more accustomed to simply stopping diabetes medications.

With regard to the cut-off level of glucose needed for elective surgery to proceed, the authors have stated the random glucose level of $12 \mathrm{mmol} \cdot \mathrm{L}^{-1}$ is a reasonable target, despite a wide and variable range of acceptance in practice. Nevertheless, I argue that it may be better to consider hemoglobin-A1C (Hb-A1C) level rather than a random glucose level as it would give an overall idea about the control of diabetes on a more long-term basis. Indeed, a recent review article by Palermo $\mathrm{et} \mathrm{al}$. has suggested that the patients with $\mathrm{Hb}-\mathrm{A} 1 \mathrm{C}>8$ should be treated vigorously (and preferably by an endocrinologist) to reduce complications as well as the duration of stay in the hospital, based on many studies conducted on various populations. ${ }^{5}$

Last but not least, it is indeed unfortunate that only $9 \%$ of the intended target population responded to this survey. It is uncertain if it would have produced different results if the response rate had been different (e.g., 91\%).

Conflict of interest None declared.

Editorial responsibility This submission was handled by Dr. Hilary P. Grocott, Editor-in-Chief, Canadian Journal of Anesthesia.

\section{References}

1. Brown $R$, Siddiqui $U$, Paul J. A survey: perioperative diabetes medications and glucose control-time to re-examine management? Can J Anesth 2019; 66: 621-2. 
2. Umpierrez GE, Gianchandani $R$, Smiley $D$, et al. Safety and efficacy of sitagliptin therapy for the inpatient management of general medicine and surgery patients with type 2 diabetes: a pilot, randomized, controlled study. Diabetes Care 2013; 36: 3430-5.

3. Pasquel FJ, Gianchandani R, Rubin DJ, et al. Efficacy of sitagliptin for the hospital management of general medicine and surgery patients with type 2 diabetes (Sita-Hospital): a multicentre, prospective, open-label, non-inferiority randomised trial. Lancet Diabetes Endocrinol 2017; 5: 125-33.
4. Garg R, Schuman B, Hurwitz S, Metzger C, Bhandari S. Safety and efficacy of saxagliptin for glycemic control in non-critically ill hospitalized patients. BMJ Open Diabetes Res Care 2017; 5: e000394.

5. Palermo NE, Garg R. Perioperative management of diabetes mellitus: novel approaches. Curr Diab Rep 2019; 19: 14.

Publisher's Note Springer Nature remains neutral with regard to jurisdictional claims in published maps and institutional affiliations. 